\title{
O APRENDIZADO DO CUIDAR DA FAMÍLIA DA CRIANÇA HOSPITALIZADA POR MEIO DE ATIVIDADES GRUPAIS ${ }^{1}$
}

\author{
THE LEARNING OF TAKING CARE OF THE CHILD'S FAMILY HOSPITALIZED BY GROUP ACTIVITIES
}

\section{EL APRENDIZAJE DEL CUIDAR DE LA FAMILIA DEL NIÑO HOSPITALIZADO POR MEDIO DE ACTIVIDADES GRUPALES}

\section{Carla Natalina da Silva Fernandes ${ }^{2}$, Lourdes Maria da Silva Andraus ${ }^{3}$, Denize Bouttelet Munari ${ }^{4}$}

RESUMO: Este estudo teve como objetivo conhecer o aprendizado do aluno no processo de cuidar do familiar acompanhante da criança/adolescente hospitalizado. Trata-se de um estudo descritivo exploratório, de abordagem qualitativa. A investigação foi realizada com 12 acadêmicos da $5^{\mathrm{a}}$ série do curso de graduação em enfermagem da Faculdade de Enfermagem da Universidade Federal de Goiás. Para a coleta de dados, utilizamos uma entrevista semiestruturada aplicada aos alunos entre os meses de dezembro 2004 a janeiro de 2005. A análise foi fundamentada nos pressupostos da análise temática de BARDIN (1977) que permitiu a identificação de duas categorias: 1)Entendendo a formação acadêmica dos enfermeiros para o cuidado às famílias, que explora o modo como os alunos percebem a sua formação para cuidar da criança e de sua família e 2) O significado do cuidar por meio das atividades grupais, que destaca os aspectos do aprendizado da utilização das atividades grupais junto aos familiares. Ressaltamos que, na perspectiva dos alunos, essa foi uma experiência importante por proporcionar momentos de aproximação e facilitação do cuidado oferecido à criança e sua família, bem como possibilitou a reflexão sobre as habilidades necessárias para o pensar e fazer o cuidado humanizado no contexto das relações estabelecidas entre família-cliente-enfermeiros. Os alunos apontam ainda alguns aspectos que sentem necessidade de melhorias por parte dos docentes e da própria instituição de saúde, mostrando a relevância de considerarmos a avaliação do aluno um instrumento para constante renovação das práticas pedagógicas, assim como para a melhoria da qualidade da assistência em saúde.

PALAVRAS CHAVES: Enfermagem Pediátrica; Educação Superior; Processos Grupais.

SUMMARY: This study aims to know the student's learning in the process of taking care of the relative companion of hospitalized child/adolescent. This is a qualitative design of descriptive and exploratory research. The investigation was accomplished with 12 academic of the $5^{\text {th }}$ of the nursing graduation class at the Federal University of Goiás. The data collection was made by a semi-structured interview applied to the students from December 2004 to January 2005. The analysis was based on thematic analysis which allowed the identification of two categories: 1)
Understanding nurses academic formation to care families, that it explores the way as students notices them formation to take care of the child and of her family and 2) The meaning of caring by group strategies, that detaches aspects of the learning of the use of activities in group with relatives. In the students' perspective, that was an important experience for providing moments to stay together and facilitating the care offered to the child and family, as well as it made possible the reflection about the necessary abilities to think and to do the humanized care in the context of the established relationships among family-patientnurses. The students still detach some aspects that feel need of improvements from teachers and of the health institution, showing the relevance to consider the student's evaluation as an instrument for constant renewal of the pedagogic practices, as well as for the improvement of the quality of the attendance in health.

KEY WORDS: Pediatric Nursing; Higher Education; Group Processes

RESUMEN: Este estudio tuvo como objetivo conocer el aprendizaje del estudiante en el proceso de cuidar del familiar acompañante del niño/adolescente hospitalizado. Es un estudio descriptivo exploratorio, de abordaje cualitativo. La investigación fue realizada con 12 académicos de la $5^{\mathrm{a}}$ serie del curso de graduación en Enfermería de la Facultad de Enfermería de la Universidad Federal de Goiás. Para la colección de datos, usamos una entrevista semiestructurada aplicada a los estudiantes entre los meses de diciembre de 2004 e enero de 2005.

\footnotetext{
${ }^{1}$ Trabalho vinculado ao Núcleo de Estudos e Pesquisa em Saúde Integral da Faculdade de Enfermagem - UFG.

2 Enfermeira. Mestranda do Programa de Pós-Graduação em Enfermagem-Mestrado da Faculdade de Enfermagem da Universidade Federal de Goiás. Goiânia-GO. Email: carlanatalina@pop.com.br

${ }^{3}$ Enfermeira. Doutora em Ciências da Saúde. Professora Adjunto da Faculdade de Enfermagem da Universidade Federal de Goiás. Goiânia, Goiás. E-mail: lourdes@fen.ufg.br

${ }^{4}$ Enfermeira. Doutora em Enfermagem. Professora Titular da Faculdade de Enfermagem da Universidade Federal de Goiás. Goiânia, Goiás. E-mail: denize@fen.ufg.br
} 
La análisis fue basada en los presupuestos de la análisis temático que permitió la identificación de dos categorías: 1) entendiendo la formación académica de enfermeros para el cuidado a las familias, que explora la manera como los estudiantes perciben su formación para cuidar del niño y de su familia y 2) El significado del cuidar a través de las actividades de grupos, que destaca los aspectos del aprendizaje de la utilización de las actividades del grupo cerca a los familiares. En la perspectiva de los estudiantes, esa fue una experiencia importante proporcionando momentos de acercamiento y facilitación del cuidado ofrecida al niño y su familia, así como posibilitó la reflexión de las habilidades necesarias para el pensar

\section{INTRODUÇÃo}

O processo de internação hospitalar pode gerar na criança/adolescente e na sua família sentimentos ambíguos, os quais podem se relacionar com a dor e a cura, o que faz do hospital um local para a troca de experiências dolorosas. O manejo desta situação se constitui numa tarefa complexa para a família, a criança/adolescente hospitalizados bem como para a equipe de saúde que presta a assistência, já que todos estão envolvidos neste processo (COLLET \& OLIVEIRA, 2002).

A necessidade dos pais participarem no cuidado dos filhos doentes é amplamente reconhecida desde o Relatório Platt, publicado em 1959 na Inglaterra. Esse documento versava sobre o bem-estar da criança no hospital e já indicava como benéfica a presença dos pais acompanhando o filho doente (LONDON, 1959).

A doença da criança faz com que a família também se sinta doente e até mesmo culpada pelo acontecimento, pois a doença é um fator de desajustamento que provoca, precipita ou agrava desequilíbrios psicoemocionais na criança e na família (CHIATTONE apud CAMON, 1984).

A observação da convivência no espaço hospitalar entre familiares e profissionais de saúde tem sido um desafio, apesar desses últimos reconhecerem as dificuldades que a família enfrenta bem como a importância da presença dos pais na recuperação da criança e o direito de permanecerem ao lado do filho. COLLET \& OLIVEIRA (2002) observaram que no cotidiano da assistência, há uma manifestação explícita de conflitos entre familiares e equipe de enfermagem, concluindo que o uso de estratégias de ambas as partes para tornar as relações mais saudáveis devem ser constantes já que, são complexas e permeadas pelo exercício do poder da equipe sobre os acompanhantes.

Nesse sentido, para que a assistência de enfermagem às crianças e adolescentes bem como de suas famílias tenha qualidade, é necessário que y hacer el cuidado humanizado en el contexto de las relaciones establecidas entre familia-clienteenfermeros. Los estudiantes todavía apuntan algunos aspectos que sienten necesidad de mejoras por parte de los maestros y de la propia institución de salud, mostrando la relevancia de nosotros considerarnos la evaluación del estudiante como un instrumento para la renovación constante de las prácticas pedagógicas, así como para la mejora de la calidad de la asistencia en la salud.

PALABRAS CLAVE: Enfermería Pediátrica; Educación Superior; Procesos de Grupo.

os profissionais façam uma revisão de conceitos e atitudes perante si e àqueles que recebem seus cuidados.

O cuidado de enfermagem não deve ser desvinculado da família e de suas necessidades, o que implica no domínio de informações teóricas específicas e ao desenvolvimento de uma sensibilidade especial para lidar com esta clientela (LACAZ \& TYRREL, 2003).

Portanto é fundamental compreender a família como mediadora da criança/adolescente no hospital, já que, ela é porta-voz das preocupações e sentimentos daqueles que acompanham, transmitindo à equipe os sinais e as mensagens enviadas pela criança/adolescente. Estes sinais podem auxiliar os profissionais a rever sua conduta e promover mudanças na assistência, adequando o mundo do hospital às necessidades da criança (MOTTA, 1998).

No Brasil, a partir da aprovação do Estatuto da Criança e do Adolescente (ECA) (BRASIL, 1992) em 1991, uma nova proposta para o atendimento a esta clientela é desencadeada, na qual as instituições de saúde são obrigadas a aceitar uma pessoa da família acompanhando sua criança/adolescente durante a internação.

Com este estatuto, vários foram os desafios para o processo de inclusão do familiar no ambiente hospitalar, se configurando em objeto de investigação por diversas áreas do conhecimento, na tentativa de compreender e transpor barreiras nas relações interpessoais, na readequação de infra-estrutura das unidades de internação para acomodar o familiar e habilitar os profissionais de saúde para oferecerem assistência adequada ao binômio criança/adolescente e família. Em função deste processo de mudança na forma de cuidar em pediatria, cabe às instituições de ensino a revisão de seus currículos e de estratégias de ensino para a formação dos futuros profissionais para esse tipo de abordagem centrado na criança e na família.

No planejamento da assistência e das ações de enfermagem já é explícita a preocupação em cuidar 
da família, mas os resultados na prática não têm se mostrado tão eficientes. Grande parte dessa problemática está relacionada ao despreparo do profissional para a compreensão da família, suas necessidades e dinâmica, já que tais conteúdos ainda são escassos nos currículos dos cursos de graduação em enfermagem. Além da compreensão da dinâmica familiar, é preciso entender que as frustrações, a tristeza e o ódio associados à doença de uma criança podem levar alguns familiares a se tornarem desconfiados, agressivos e, em alguns casos, até violentos (MALDONADO \& CANELLA, 2003).

Em nossa experiência com a prática do cuidado a crianças/adolescentes e seus familiares temos observado um despreparo dos profissionais para abordarem de maneira segura e eficaz a família no cotidiano da internação hospitalar, faltam-lhes noções de áreas do conhecimento que dêem suporte para trabalhar com a dor e o sofrimento do outro e para estabelecer processos efetivos de comunicação.

A inclusão da família no cuidado do enfermeiro requer deste profissional uma postura aberta e atenta às interações e aos impactos das vivências que ocorrem no ambiente hospitalar para o conhecimento da dinâmica e formas de adaptações diversas porque passam as famílias durante o processo de hospitalização de seus filhos. Contudo, nem sempre estes saberes são suficientes para cuidar da família, pois esse cuidado acontece em um contexto interacional de vivências compartilhadas entre família, criança e equipe de saúde (WERNET \& ÂNGELO, 2003).

Estes aspectos são fundamentais para pensarmos a assistência a família, pois sem dúvida alguma essas pessoas devem receber cuidados focados numa escuta atenta e sensível da sua dor e perplexidade frente ao fato da criança estar internada, visando encontrar saídas possíveis dentro do contexto de suas vidas para a resolução das dificuldades existentes durante 0 período de internação e o compartilhamento das alegrias (SILVA, 2000).

Este cenário sugere a busca de estratégias que considerem estas questões complexas como a habilitação dos profissionais para lidar com a família, a iniciativa dos gestores das instituições para o investimento em infra-estrutura que assegure aos acompanhantes condições mínimas de permanência com conforto e bem-estar na unidade, a utilização de estratégias de cuidado aos familiares, como por exemplo, as atividades grupais, que oferecem espaço para a escuta e acolhimento (ANDRAUS et al, 2004; RAMALHÃO \& DUPAS, 2003).

No entanto, para que a assistência seja contemplada nessa dimensão é fundamental a formação de profissionais em atividades de educação continuada e também durante a graduação, que seja focada para a necessidade de cuidar da criança e/ou adolescente internado articulado ao cuidado de sua família.

Em nossa experiência acadêmica e docente, com os alunos do curso de graduação em enfermagem, temos várias oportunidades de vivenciar $\mathrm{o}$ atendimento à criança e ao adolescente bem como de suas famílias em diversos campos de prática como: unidades de internação, ambulatórios, postos de saúde e escolas. Sentimos que quanto maior o envolvimento com a criança/adolescente e a sua família melhor será o feedback que estes nos oferecem em relação à assistência prestada e aos vínculos estabelecidos.

Especialmente na assistência aos pais, utilizamos há alguns anos a tecnologia de grupo durante as aulas práticas da disciplina Enfermagem Materno Infanto Juvenil, do Curso de Graduação da Faculdade de Enfermagem da Universidade Federal de Goiás, na Unidade de Internação Pediátrica de um Hospital Público de Ensino. Essa estratégia é planejada e coordenada pelos próprios alunos e supervisionadas pelo professor, com objetivo de minimizar a ansiedade dos pais, esclarecer dúvidas, orientá-los sobre as normas e rotinas da unidade bem como fazer educação em saúde. As atividades são propostas a partir de encontros que ocorrem quinzenalmente na própria unidade de internação pediátrica, e são avaliadas ao final de cada encontro pelos participantes e separadamente pelos alunos. Observamos que a utilização da tecnologia grupal na abordagem dos familiares, experienciada pelos acadêmicos durante as aulas práticas na Unidade de Internação tem trazido grandes oportunidades de aprendizagem tanto para as famílias como para alunos e professores (ANDRAUS et al, 2004).

Essas ocasiões têm se tornado um importante momento para o exercício do cuidado humanizado, e, embora essa seja uma prática há anos, não temos uma avaliação sistemática desse aprendizado, nem a dimensão exata do seu significado na formação do enfermeiro. Assim, nos propusemos neste estudo conhecer detalhadamente como 0 aluno de graduação em Enfermagem experimenta o aprendizado do cuidado humanizado ao familiar da criança e lou adolescente hospitalizados na perspectiva da abordagem grupal.

Para tanto delimitamos como objetivo deste estudo conhecer o aprendizado do aluno no processo de cuidar do familiar acompanhante da criança/adolescente hospitalizado e, como objetivos específicos Identificar de que maneira os acadêmicos de enfermagem, que já realizaram a disciplina Enfermagem Materno Infanto-Juvenil do Curso de Graduação em Enfermagem na Universidade Federal de Goiás, percebem a formação recebida na graduação em Enfermagem para cuidar da família da criança/adolescente hospitalizado; e verificar as percepções destes acadêmicos de enfermagem, acerca da sua participação na assistência à família da 
criança/adolescente hospitalizado por meio de atividades grupais;

\section{METODOLOGIA}

Pesquisa descritiva exploratória, de abordagem qualitativa. Os estudos exploratórios descritivos baseiam-se na coleta de descrições detalhadas das variáveis do fenômeno retratado. Os dados justificam e avaliam a realidade ou servem para sugerir e implementar soluções, em nosso caso no sistema de saúde e nas propostas educacionais em enfermagem (MINAYO \& SANCHES, 1993).

Para LOBIONDO-WOOD \& HABER (2001) a pesquisa qualitativa é particularmente bem adequada ao estudo da experiência humana em saúde, já que os métodos qualitativos concentram-se no todo dessa experiência e o sentido atribuído pelos indivíduos que a vivem, permitindo uma compreensão mais ampla e um insight mais profundo a respeito dos comportamentos humanos complexos, como estes são apresentados aos sentidos, trabalhando valores, crenças, representações, atitudes, opiniões e aprofundando a complexidade dos fenômenos (MINAYO, 1993).

\section{Local de estudo}

O estudo foi desenvolvido na Faculdade de Enfermagem da Universidade Federal de Goiás (FEN/UFG), em Goiânia (GO), no período de março de 2004 a janeiro de 2005, vinculado à disciplina Enfermagem Materno-Infanto Juvenil, que é oferecida na $4^{a}$ série do curso de graduação em Enfermagem da FEN/UFG, com carga horária de 420 horas, sendo 50 horas desenvolvidas na unidade de internação pediátrica de um hospital público de ensino, no qual os alunos têm oportunidade de prestar assistência à criança/adolescente e seu familiar acompanhante.

\section{Caracterização dos sujeitos}

Participaram da pesquisa 12 alunos do Curso de Graduação em Enfermagem da UFG, que haviam concluído a disciplina Enfermagem Materno-Infanto Juvenil entre os anos de 2003 e 2004, desenvolveram atividades grupais junto aos familiares acompanhantes das crianças/adolescentes hospitalizados na unidade e que se dispuseram a participar da pesquisa voluntariamente, após serem esclarecidos os objetivos, riscos, benefícios da pesquisa e assinado o termo de Consentimento Livre e Esclarecido.

\section{Aspectos éticos}

Esta pesquisa foi aprovada pelo Comitê de Ética em Pesquisa Médica Humana e Animal do Hospital das Clínicas da Universidade Federal de Goiás. (CEPMHA/HC/UFG), para avaliação e garantia de que fossem resguardadas as orientações da
Resolução 196/96 do CONEP para pesquisa com seres humanos. Protocolo de identificação número: 088/04

\section{Coleta e tratamento dos dados}

A coleta de dados foi realizada pelas pesquisadoras após contato com os acadêmicos para agendamento prévio e a garantia do anonimato e a confidencialidade das informações obtidas. Para tanto, foram realizadas entrevistas individuais, orientadas por um roteiro semi-estruturado e em local reservado. As entrevistas foram gravadas, com o consentimento dos participantes, para assegurar a fidedignidade dos dados que foram transcritos na seqüência.

A coleta de dados ocorreu entre os meses de dezembro de 2004 a janeiro de 2005, ocasião em que todos os alunos já tinham terminado a disciplina. O número de entrevistados foi determinado pelos critérios de saturação dos dados estabelecidos por BARDIN (1977)

Os dados foram submetidos a análise temática de conteúdos, segundo os pressupostos de BARDIN (1977), que prevê a organização da análise em torno de três pólos: (1) a pré-análise, fase onde ocorre a organização propriamente dita, corresponde ao período de intuições, que objetivam operacionalizar e sistematizar as idéias iniciais, conduzindo ao plano de análise; (2) a exploração do material e (3) tratamento dos resultados obtidos e interpretação. Nesta fase os resultados brutos são tratados de maneira a serem significativos e válidos para viabilizar a categorização que é "uma operação de classificação de elementos constitutivos de um conjunto, por diferenciação e, seguidamente, por reagrupamento segundo o gene, com critérios previamente definidos." (BARDIN, 1977. p.117) e a inferência das categorias encontradas bem como a análise dos temas que surgiram nas mesmas.

\section{RESULTADOS E DISCUSSÃO}

Dentre os anos de 2003 e 2004, 96 alunos do Curso de Graduação em Enfermagem da Universidade Federal de Goiás, concluíram a disciplina Materno-infanto-juvenil, destes, 32 alunos desenvolveram atividades grupais junto aos familiares das crianças hospitalizadas. Deste universo foram entrevistados 12 acadêmicos em sua maioria do sexo feminino, apenas um do sexo masculino. A faixa etária compreendida entre 20 e 45 anos, média de idade de 24 anos; apenas um com estado civil casado. A maior parte dos alunos é procedente do Estado de Goiás. A renda familiar predominante é maior que seis salários mínimos.

Após a leitura das entrevistas e seguindo a proposta metodológica descrita anteriormente, identificamos duas categorias centrais: "Entendendo a formação acadêmica dos enfermeiros para o cuidado as famílias" e "O significado de cuidar das famílias por 
meio de atividades grupais". Para melhor compreensão dos dados essa última categoria foi desdobrada em três sub-categorias: "Vivenciando o grupo"; "Entendendo alguns sentimentos que permeiam as interações humanas" e "Facilidades e dificuldades na coordenação das atividades grupais".

\section{Entendendo a formação acadêmica dos enfermeiros para o cuidado às famílias}

Esta categoria descreve o modo como os acadêmicos consideram a formação recebida na disciplina correspondente ao ensino da prática pediátrica em enfermagem, especificamente, para o cuidado das famílias acompanhantes de crianças e adolescentes hospitalizados.

A maioria afirma estar satisfeita com a sua formação, no entanto, considera que o ensino ainda passa por transições, pois embora mantenha seu eixo focado na importância do cuidado às pessoas, o ensino e a prática focalizam, prioritariamente, o cuidado centrado na criança.

"A disciplina foi fundamental e ela passou o que tinha que passar, como abordar a família, o jeito que você tem que falar com a família, o cuidado de dizer certas coisas para não assustar ". (E3)

"Acho que a abordagem que nos tivemos não foi 100\% para estar trabalhando com a família, a formação na disciplina é mais voltada para estar atendendo a criança ali na prática, quais os problemas da criança, essas coisas técnicas. Agora a questão de lidar com a família, o que eu pude fazer lá não foi baseado só no que eu aprendi na pediatria, mas no que eu aprendi desde o primeiro ano, o que a gente aprende sobre humanização, sobre como tratar o familiar, não foi só especificamente da pediatria. Acho até que deveria ser melhor." (E4)

Um aspecto importante revelado pelo estudo é o reconhecimento dos alunos de que a abordagem da família é focalizada durante todo o curso de graduação em enfermagem pelas diversas disciplinas que os acadêmicos cursam.

\section{"Acho que nosso curso em geral independente da disciplina sempre mostra isso de dar atenção para a família." (E2)}

Neste caso, é importante refletirmos sobre o que abordam DAMAS et al (2004) no que tange o cuidado do cuidador, seja ele família ou profissionais, que acabam sofrendo grande desgaste emocional no cuidado as pessoas, portanto necessitam de cuidado humano que poderá ser suprido nas relações que estabelece com as pessoas, afirmam que para alcançar o sucesso no processo de aprender a cuidar de quem cuida e para aprender a construir um ambiente de trabalho saudável, deve se iniciar na graduação. Desta maneira, percebemos na fala dos acadêmicos uma preocupação da instituição formadora no sentido de atender as necessidades do cuidador direto da criança, ou seja, sua família, no entanto nos perguntamos se o cuidado ao cuidador profissional se estabelece na mesma medida.

Os depoimentos apontam a importância da abordagem oferecida pela instituição formadora, de modo geral, para a construção do perfil do profissional durante todo o processo para formar o enfermeiro comprometido com o cliente e sua família. Parece que isso tem permitido aos alunos oportunidade de uma avaliação crítica do seu aprendizado teórico-prático recebido na disciplina Materno-Infanto-Juvenil, responsável pelos conteúdos de assistência de enfermagem pediátrica.

"Essa disciplina deixa bem claro que a gente não deve dar assistência só à criança, mas, à família também, me deu essa formação, que a gente tem que esclarecer, apresentar a equipe, dar apoio em todos os sentidos." (E12)

Os acadêmicos têm clareza que para tornar a sua prática profissional diferenciada devem procurar ampliar as discussões e referenciais teóricos acerca da temática do cuidado por meio de atividades grupais, da humanização e do enfoque da família a partir de seu próprio interesse e iniciativa.

"Eu acho que a faculdade ela te dá o básico, você que tem que buscar novos horizontes, você que tem que buscar ser diferente." (E3)

Outro aspecto salientado pelos acadêmicos para melhorar a relação ensino-aprendizagem dos anos seguintes, é utilizar a experiência que vivenciam em outras disciplinas da área de Saúde Mental, que utilizam a Educação de Laboratório como instrumento para desenvolver habilidades de coordenação dos grupos à partir de experiências vividas no grupo. Na perspectiva dos alunos, o uso dessa tecnologia, poderia facilitar o entendimento das relações criançafamília-equipe de saúde, o que, consequentemente, permitiria o cuidado integrado a criança e família, como é possível verificar na fala seguinte.

"Aulas voltadas mais pra isso, como trabalhar com as famílias das crianças, entendeu como a gente tem as aulas de saúde mental no $5^{\circ}$ ano? Se fosse antes a gente poderia se sair bem melhor. Então acho que poderia ser mais voltado, trazer mais histórias para a gente discutir, técnicas para estarmos trabalhando com essas mães, porque quando fomos planejar não tínhamos tantas idéias como a 
gente teve nesse ano, no $5^{\circ}$ ano, se eu fosse fazer hoje eu iria utilizar muitas coisas nesse sentido." (E4)

Sobre isso, MORIN (2002) salienta que é preciso ensinar aos indivíduos princípios que permitam enfrentar os imprevistos, o inesperado, a incerteza e modificar seu desenvolvimento, em virtude das informações adquiridas ao longo do tempo. Para a abordagem de tais princípios, no entanto, é fundamental por parte do docente uma atitude reflexiva e transformadora diante da sua prática diária, de tal modo que ela valorize os talentos humanos e as expressões necessárias para o cuidado (SILVA, 2000; WERNET \& ANGELO, 2003; ESPERIDIÃO \& MUNARI, 2004; DAMAS et al, 2004)

Pensar na educação e fazê-la de uma forma a contemplar os recursos internos e as habilidades dos acadêmicos para o cuidado da família é essencial para a transformação da práxis no cuidado em enfermagem. Os participantes dessa pesquisa apontaram alguns caminhos para essa mudança, ressaltando a experiência em que são despertados para o fato de que a qualidade do cuidado refere-se não apenas a relação construída entre profissionalcliente-família, mas na qual todos se inter-relacionam moldando uma teia que poderá oferecer recursos saudáveis para o manejo da situação vivenciada por todos durante o período de internação da criança e ou do adolescente.

\section{O significado do cuidar por meio das atividades grupais}

De modo geral, identificamos nesta categoria, que o cuidado à criança e ou adolescentes hospitalizados só será percebido como completo se os seus familiares também o receberem. Caso isso ocorra, inevitavelmente, a relação de cuidado à criança será melhorada. Os acadêmicos priorizaram o cuidado à família como meio de cuidar da criança, no entanto, salientaram a necessidade de compreender o significado daquela situação para a família como recurso para cuidar da mesma.

Neste aspecto COLLET \& ROCHA (2004) salientam que a permanência dos pais em período integral no ambiente hospitalar, sua participação no cuidado e a natureza da relação entre crianças, pais e profissionais, têm desencadeado novas formas de organização da assistência à criança hospitalizada. Nesse cenário, o foco do cuidado é a família, sujeita a um processo de relações e intervenções para além do atendimento clínico.

A atividade grupal se mostra como recurso para o cuidado na medida em que se constitui num espaço para o conhecimento de si e fortalecimento das relações humanas, permitindo aflorar, principalmente, nestes grupos os sentimentos de coesão e universalidade (VINOGRADOV \& YALOM,
1992). O familiar, nesse contexto, percebe que todos passam por situações semelhantes, que não está sozinho ao mesmo tempo em que compartilha sentimentos de sofrimento e alegria quando os filhos se recuperam. A história dos outros familiares oferece esperança e força para continuar no acompanhamento do filho. Neste mesmo espaço, os alunos que coordenaram a atividade, demonstraram vários sentimentos e posturas diante do grupo, como responsabilidade, segurança e insegurança, empatia, sensibilidade, afetividade, cuidado e envolvimento, e adquirem maiores condições de entender a complexidade que envolve o cuidado com a família.

\begin{abstract}
"Bem eu acho que a família merece toda a atenção, porque afinal de contas a criança está ali passando por um momento que abala a estrutura familiar como um todo, não só a mãe como o pai, todo mundo passando por aquele processo que a criança está ali, está abalada, acho que é primordial a assistência a família, acho que é importante dar apoio, esclarecer as dúvidas" (E12).
\end{abstract}

No tratamento dessa categoria optamos por dividir o conteúdo emergente dos dados em três subcategorias que apresentamos à seguir.

\section{Vivenciando o grupo}

$\mathrm{Na}$ internação hospitalar do filho há uma desordem no modo da família se organizar e interpretar os acontecimentos. A doença da criança faz com que a família se sinta doente e até mesmo culpada pelo acontecimento, podendo precipitar ou agravar desequilíbrios psicoemocionais, o que requer da equipe uma interação efetiva para com esses familiares para tornar menos doloroso esse momento gerador de muito estresse (COLLET \& ROCHA, 2004).

Ao utilizarmos o grupo como recurso para o cuidado à família de crianças hospitalizadas significa introduzir mudanças na prática da enfermagem em direção a uma assistência ampliada que considere as necessidades da criança e da família, sendo importante termos sensibilidade para perceber os múltiplos determinantes que envolvem este cuidado.

A experiência da utilização das atividades grupais para o cuidado às famílias, surge da necessidade que este grupo específico têm, visto que, pouco tem sido feito no sentido de acolher os familiares no período de internação do filho, saber suas reais necessidades, angústias, medos, sentimentos em relação ao filho e estratégias para o cuidado da criança ou adolescente.

Os acadêmicos de enfermagem validaram isso, quando enfatizarem a importância das atividades grupais para fortalecer a relação profissional-famíliacliente. 
"Acho que quando você desenvolve essas atividades com os familiares fica mais fácil, você tem uma abertura maior até mesmo para você assistir o paciente, porque a família ela se sente acolhida e pode estar te ajudando em muitas coisas [...] a família pode te ajudar muito." (E3)

"Às vezes o familiar esta ali num ambiente desconhecido, está perdido, está com medo, esta fora de casa e é uma forma de você trazer ele para perto, tanto aplicando técnicas de grupo, para quebrar a tensão, quebrar o medo, como para haver interação entre os pais e os familiares, como para passar mais segurança para eles mesmo, do ambiente que eles estão e do tratamento que o filho está recebendo." (E11)

Esta atividade para os acadêmicos também propiciou momentos de alivio da tensão vivenciada pelo familiar durante a internação do seu filho, bem como estreitou os laços entre a equipe, a família e a criança possibilitando o desenvolvimento de habilidades de relacionamento interpessoal, como saber ouvir, oferecer apoio, saber falar e ter empatia.

"Depois desse grupo, desse conhecimento, dessa interação, a gente chegava na enfermaria e já tratava aquela mãe e aquela criança diferente, a gente já sabia a necessidade da mãe e da criança, a gente conheceu mais a realidade e podia intervir melhor, a gente conhecia a historia real da criança podia estar aplicando não só aquela prática, mas a estar lidando mais com o ser humano, com o cuidado, eu aprendi bastante com essa experiência para aprender a ser cuidador." (E4)

"Outra coisa importante a se falar é que a gente aprende não só conteúdos científicos teóricos, mas aprende a lidar com as pessoas, aprende que a pessoa tem medo, a família tem receio de chegar na gente pra conversar, a família se apresenta arredia, não porque ela seja assim, mas porque a gente trata a família assim sabe sem muita intimidade, e depois que a gente tem esse momento há uma abertura, então acho que tem que haver esses momentos mesmo, reunião com os grupos familiares e quebrar o estresse do ambiente hospitalar." (E3)

"Elas precisam disso mesmo, precisam de um momento para estar em grupo, para falarem o que elas estão sentindo, para aprenderem sobre alguma coisa, para olharem pro lado e falarem 'nossa tem alguém que esta passando pela mesma situação que eu', então por isso é bom este momento." (E5)
As atividades grupais associam conceitos de cuidar e de empowerment do familiar na busca do equilíbrio durante o processo de internação dos seus filhos e no fortalecimento da família para o período pós-alta hospitalar. Isso nos leva a refletir sobre o verdadeiro papel do enfermeiro na utilização desse recurso no cuidado aos familiares. Segundo SUGANO et al (2003, p 606) "o cuidado a mãe acompanhante não é utilizá-la como colaboradora do serviço de enfermagem na assistência de sua criança, e sim, por exemplo, criar grupos de apoio para pais cujos filhos estão hospitalizados".

Concordamos com as referidas autoras, pois acreditamos que o uso dessa estratégia como espaço de cuidado possibilita a família compreender parte da problemática que os envolve diretamente e indiretamente como, por exemplo, o seu papel no cuidado ao familiar hospitalizado, as informações acerca da internação, além de compartilhar a vivência das outras famílias que se encontram em situação semelhante. Isso facilita a comunicação entre os membros no momento do grupo, criando um clima emocional favorável e de apoio, fundamentalmente de caráter positivo e muito eficiente na minimização dos aspectos hostis que ocorrem durante a hospitalização das crianças e adolescentes (MUNIZ \&TAUNAY apud MELLO FILHO, 2000). Assim, os familiares acompanhantes perceberão a enfermeira como quem informa, orienta e apóia.

\section{Entendendo alguns sentimentos que permeiam as interações humanas}

Nesta sub-categoria trabalhamos os dilemas dos alunos frente aos sentimentos surgidos à partir das atividades com os familiares, especialmente, pelo fato de aprenderem a lidar com os sentimentos dos clientes e os seus ao mesmo tempo.

Houve uma preocupação por parte dos acadêmicos com o excesso de exposição dos sentimentos dos familiares no momento da atividade grupal, deixando-os sensibilizados e receosos sobre qual a melhor postura a assumir diante das questões trazidas pelos familiares. Outro sentimento presente, exposto pelos alunos é de certo despreparo para saber reagir e responder a reações dos familiares que surgiram na dinâmica grupal, principalmente, o choro.

"Também é ruim uma pessoa está se abrindo no meio de um grupo inteiro parece que todo mundo vai mexendo com as mães e elas já estão sensíveis, então não seria tão bom elas se abrirem tanto, senão iria mexer muito com todo mundo eu queria dar um jeito para não mexer tanto com os sentimentos, mas isso é uma coisa difícil de acontecer, principalmente, quando são as mães que estão falando eu tive dificuldades de agir quando elas estavam 
falando, então eu só escutava mesmo e uma palavra de conforto quando eu sabia que poderia confortá-la." (E2)

Consideramos legitimas as preocupações dos alunos e importante para que durante o aprendizado da coordenação de grupo, esses aspectos sejam tomados com muita responsabilidade e respeito ao momento do grupo para evitar a banalização do uso desse recurso (MUNARI \& RODRIGUES, 2003; ANDALÓ, 2001). O professor ao possibilitar a experiência do aluno nesse tipo de atividade deve funcionar como um supervisor atento, responsável e a postos para, diante de uma eventualidade, dar suporte ao aluno, bem como ao grupo.

Utilizar o grupo como recurso para o cuidado deixa à mostra todas as pessoas que fazem parte dele, isso inclui o próprio coordenador, nesse caso, os acadêmicos mostraram por meio de suas falas que se permitiram genuinamente a um processo de aprendizado e de autoconhecimento. Ao se colocarem empáticos diante das situações vivenciadas pelos familiares, puderam rever seus sentimentos e, entender as dificuldades $e$ compreender o significado da dor e da angústia que é cuidar de um filho doente e cuidar da família e da criança.

"Eu usei recursos que eu já tinha para coordenar o grupo, inclusive eu não acho muito fácil, porque você vai interagir com pessoas que você não conhece, à princípio. Eu tenho certa dificuldade de me aproximar, principalmente, com pessoas que eu não conheço. Não acho uma coisa fácil mas acho de extrema importância, porque é justamente isso, você promove interação, comunicação, conhecimento".(E11)

"Foi emocionante, teve momentos que eu não consegui segurar as lágrimas, mas foi bom que nós conseguimos conduzir a conversa pra não ficar só no despejar sentimentos, e como abordar, como se comportar, sem ser autoritária não cortar as pessoas quando elas estão falando, isto basicamente eu aprendi, e valorizar o sentimento e o sofrimento das pessoas que estão lá, porque até um certo momento eu não tinha percebido como que a mãe de uma família sofre, principalmente, quando é uma criança que está lá no hospital." (E10)

Percebemos que, mesmo enfrentando dificuldades durante as atividades, os acadêmicos consideraram a experiência ímpar, por permitir a descoberta de novas formas de utilizar seus recursos e potencialidades. Esse movimento parece estimular a autoconfiança em suas habilidades, em seu potencial para lidar com suas fraquezas, o que favorece a relação interpessoal estabelecida com os familiares. Nesse sentido, o espaço do grupo legitima um momento de encontro que, ao mesmo tempo em que é propicio para a exposição de angústias e tensões dos familiares, permite ao aluno exercitar a escuta e o apoio (MUNARI \& RODRIGUES, 2003). Neste cenário, o cuidado é vivido de modo que abrange a todos, quem é cuidado e quem cuida (PAULI \& BOUSSO, 2003).

Ao enfrentar as adversidades da atividade grupal o aluno parece compreender que ao partilhar com os pais as suas experiências, escutá-los e acolhê-los verdadeiramente, pode ampliar o contexto do cuidado, o que the oferece noção mais abrangente e articulada, do que e como, este é experimentado e a repercussão disso para as crianças, os adolescentes e pais com experiência de hospitalização (CASETE \& CORRÊA, 2005).

A fala abaixo, de uma aluna que era mãe, demonstrou que houve empatia na relação com os pais sendo este fato positivo para a compreensão de alguns sentimentos dos familiares:

"O fato de eu ser mãe, já ter experiência, você já consegue enxergar mais além do que as meninas que não são mães e não tem experiência, acho que pra mim foi muito válido" (E9)

Os dados trazidos nesta sub-categoria nos mostram a importância da busca do autoconhecimento por parte do profissional em formação, o que é discutido por DAMAS et al (2004) como um fundamento para o cuidado integral.

\section{Facilidades e dificuldades na coordenação das atividades grupais}

Nesta sub-categoria destacamos na fala dos sujeitos alguns fatores facilitadores e dificultadores no desenvolvimento das atividades grupais no momento da aula prática. Os alunos apontaram como aspectos facilitadores desta experiência o apoio da equipe de enfermagem para a realização da atividade grupal com os familiares, no sentido de oferecerem suporte externo no período em que o grupo se reunia além de disponibilizarem alguns materiais necessários. Alguns fizeram ainda referências ao aprendizado que receberam nas outras disciplinas do curso de graduação como saúde mental, o planejamento e a execução desta atividade com pessoas afins e a disposição dos familiares em participarem da atividade grupal.

"As facilidades foram a proximidade do hospital, o grupo de estágio era muito bom, tudo que a gente falava todo mundo aceitava, isso foi um ponto facilitador, a disponibilidade das enfermeiras em ajudarem a gente também 
e algumas mães ajudaram dando idéias e tendo aceitação, também os próprios alunos que coordenaram no sentido de comunicação, interação, a Faculdade propicia isso pra gente então isso foi facilitador, o que a gente aprendeu sobre grupo em Saúde Mental I, Saúde Mental II e até mesmo em outras matérias foram pontos facilitadores para isso." (E5)

Neste aspecto fica nítida a importância do conteúdo de relações interpessoais trabalhado na graduação em enfermagem e de noções sobre condução de grupos para o êxito das atividades. Da mesma maneira, destacamos que o ensino também privilegia o cuidado as famílias e a articulação com a instituição de saúde e a equipe de enfermagem como aspectos facilitadores.

Os aspectos limitadores da experiência estão ligados as limitações do espaço físico, pouca orientação no momento de planejamento da atividade, além de fatores estressores como a preocupação dos pais com o horário, já que, o único horário disponível para a realização desta atividade podia coincidir com o horário da medicação ou da visita médica.

"Lá na pediatria do hospital não tem um lugar específico reservado para o grupo e não tem espaço físico, então fechamos um lugar com uma cortina e toda hora tinha que entrar alguém para pesar uma criança então atrapalhava, desviava a atenção de todo mundo, então isso foi um fator que dificultou." (E3)

"[..] falta de tempo, porque a gente gostaria de mais tempo para estar lidando com esses grupos mas o que a gente vê ali que as mães ficavam preocupadas, com o horário da medicação, de estar na reunião na hora da medicação e a preocupação com a criança que estava lá fora, mas não foi nada que atrapalhou tanto."(E4)

A questão da adequação da infraestrutura para a realização desse tipo de atividade é fundamental para o bom andamento e condução dos encontros. Esse aspecto, quando não bem dimensionado pode colocar em risco todo o planejamento, conforme o que nos aponta RIBEIRO \& MUNARI (1998) e MUNARI, RIBEIRO \& LOPES (2002).

Outro aspecto levantado na fala dos alunos diz respeito a figura do professor que acompanha as aulas práticas que, ora surge como facilitador, ora como inibidor na condução da atividade. Isso pode servir de um alerta para o corpo docente, pois o cuidado com o suporte e orientação para a realização das atividades, bem como um planejamento adequado são fatores que podem colocar a atividade em risco, caso não haja uma atenção adequada (MUNARI \& RODRIGUES, 2003).

"Fui me soltando aos poucos e também a gente ia falar uma coisa e a professora não gostou e ela deixou a gente muito nervosa, então na hora ficou parecendo como se a gente tivesse improvisado. Mas o que aconteceu é que a professora que participou na reunião não acompanhava a gente, quem acompanhava era a que tinha visto o planejamento." (E8)

"A dificuldade de ser o primeiro grupo, de não conhecer a realidade da pediatria e às vezes a professora cobrar uma coisa que a gente não tinha tanta segurança, faltou um pouco ela demonstrar e o momento da gente discutir com as mães, nós começamos a conversar, mas teve um momento que a gente travou não sabia mais o que fazer. Aí sim a professora conduziu e depois no final ela deu muitas dicas, foi bom." (E10)

SANTEIRO et al (2004) alertam em seu estudo que, a postura do docente pode ser tanto facilitadora, quanto inibidora da criatividade. Se considerarmos que o trabalho grupal requer uma boa dose de criação e domínio de um processo dinâmico, é fundamental que a postura do docente seja a mais consoante possível para manter um ambiente propício para a expressão do cuidado criativo e espontâneo.

As falas dos alunos ainda reforçam a idéia, de que o ensino na prática da enfermagem também deve ser conduzido com sensibilidade, que priorize o aluno como sujeito de cuidado naquele momento (ESPERIDIÃO \& MUNARI, 2004). Considerando o aprendizado do manejo de grupos, em particular, MUNARI et al (2005) sinalizam que é fundamental ao professor uma atitude positiva e aberta para correr os riscos, junto com o grupo. Essa experiência por mobilizar muitos sentimentos, pode ajudar o aluno a superar obstáculos e descobrir suas habilidades.

\section{CONSIDERAÇÕES FINAIS}

Ao retomarmos os objetivos deste estudo, compreendemos que o aprendizado do acadêmico de enfermagem frente à experiência de cuidar dos familiares de crianças e adolescentes hospitalizados através das atividades grupais, revela que os alunos atribuem grande importância a essa experiência pelas possibilidades de aprendizado, para a construção de uma relação empática entre os familiares e equipe, familiares-familiares e equipe-criança. Alguns aspectos foram destacados como pontos facilitadores no aprendizado como o amparo do serviço de enfermagem local, a formação recebida nas disciplinas durante a graduação em enfermagem, a aceitação dos familiares em participar da atividade 
proposta e a afinidade entre o grupo coordenador. Os fatores dificultadores foram a inexistência de ambiente específico para realizar a atividade grupal no local onde realizaram as aulas práticas, o pouco tempo, a ansiedade de alguns familiares quanto aos acontecimentos externos à reunião, como o que estaria acontecendo à criança naquele momento, a passagem da visita médica ou horário de medicação no momento do encontro.

Dentre os aspectos que podem ser melhorados no ensino da disciplina que trata do ensino dos conteúdos referentes ao cuidado materno-infantojuvenil, com vistas a favorecer uma melhora do atendimento dedicado aos familiares no momento de hospitalização do filho bem como para estarem com mais segurança para utilizar o recurso grupal como instrumento de cuidado, algumas sugestões foram apontadas pelos acadêmicos, como, aulas que aprofundassem a discussão entre teoria e prática sobre o cuidado aos familiares modificando o foco de cuidado para a criança e a família. Contudo, eles valorizaram a formação recebida durante toda a graduação no que tange a humanização das relações estabelecidas com cliente-família-equipe.

Neste sentido, consideramos que as propostas de humanização em saúde também envolvem repensar o processo de formação do profissional, ainda centrado, predominantemente, no aprendizado técnico e individualizado, com tentativas muitas vezes isoladas de exercício da crítica, criatividade e sensibilidade levando a cristalização dos sentimentos do profissional na construção de uma relação de ajuda eficiente aos usuários dos serviços de saúde bem como seus familiares.

Os dados mostram ainda, que é fundamental reconhecer o apoio do grupo como espaço de troca e experiência, vivendo-o como agente de transformação. Segundo MUNARI \& RODRIGUES (2003) quanto mais houver acolhimento e solidariedade entre os membros do grupo, maiores as possibilidades de fortalecimento e amadurecimento dos indivíduos.

Ao pensarmos o cuidado à família da criança hospitalizada, podemos dizer que essa estratégia pode refletir no progresso do processo de cura da criança e do adolescente hospitalizados, ou ao menos, minimizar o estresse decorrente dessa experiência como afirmam ANDRAUS et al (2004), uma vez que, a presença dos pais na enfermaria constitui-se num processo complexo para os profissionais que cuidam da criança hospitalizada, pois, implica na reorganização do processo de trabalho em níveis teóricos e práticos, já que, muitos desses profissionais não foram preparados para oferecer cuidado também às famílias.

Outro fato importante a considerar, é que, a permanência da família está imprimindo uma outra dinâmica ao processo de cuidado em pediatria, pois, os familiares não estão desenvolvendo apenas habilidades técnicas para o cuidado, mas conhecendo o cotidiano do hospital e da terapêutica e, lentamente, reivindicam participação na assistência para além dos cuidados básicos como alimentação e higiene. O que significa que os cidadãos passam a exercer melhor o seu papel reivindicando e questionando sobre situações que não tem conhecimento.

A presença da família durante a hospitalização do filho, gera nos acadêmicos um sentimento de empatia, o que provoca sensações de compaixão, um dos ingredientes para o cuidado humano, e sentemse frustrados quando deparam com a dicotomia entre teoria e prática.

A assistência centrada na criança e na família ainda é algo incipiente e que passa também pelo âmbito da motivação pessoal. A convivência constante dos enfermeiros com a família tem sensibilizado esta categoria para a experiência do cuidado, no entanto, nessa relação com a família, têm experimentado a falta de confiança em si mesmos, promovendo uma incoerência entre o pensar e o agir de alguns profissionais de enfermagem.

A temática do cuidado às famílias de crianças e adolescentes hospitalizados por meio de atividades grupais merece atenção especial por envolver questões amplas que vão desde a concepção de cuidado, de família até a atividade grupal como recurso utilizado pelo enfermeiro.

Neste sentido, devemos considerar que as propostas de humanização em saúde envolvem o processo de repensar a formação dos profissionais de saúde para que possam encontrar novas alternativas de cuidar, promovendo mudanças nas pessoas que convivem e recebem seus cuidados, conscientes de que as mudanças ocorrem no momento em que as pessoas apoderam-se de seu papel junto ao ambiente em que convivem e passam a fomentar a construção da sociedade que desejam, baseados na solidariedade, na compreensão e busca da felicidade coletiva respaldada na ética, garantindo que isto não se torne uma utopia, mas um ideal possível de se tornar realidade.

Desejamos que os resultados desta pesquisa ofereçam subsídios para o direcionamento das ações no ensino e na prática do cuidado autêntico ao familiar da criança/adolescente hospitalizados.

\section{REFERÊNCIAS BIBLIOGRÁFICAS}

ANDALÓ, C.S.A. O papel de coordenador de grupos. Psicologia USP, v. 12, n. 1, p. 135-152, 2001.

ANDRAUS, L.M.S.; OLIVEIRA, L.M.A.C.; MINAMISAVA, R.; MUNARI, D.B.; BORGES, I.K. Ensinando e aprendendo: uma experiência com grupos de pais de crianças hospitalizadas. Revista Eletrônica de Enfermagem. v. 6, n. 1, p. 104-109, $2004 . \quad$ Disponível em: http://www.fen.ufg.br/revista/revista6 1/pdf/r2 pais.pd f: [Acesso em 20 set. 2005] 
BARDIN, L. Análise de Conteúdo. Lisboa: Edições 70, 1977.

BRASIL, Ministério do Desporto e Lazer. Estatuto da Criança e do Adolescente. Brasília, DF. 1992.

CASETE, J.C.; CORRÊA, A.K. Humanização do atendimento em saúde: conhecimento veiculado na literatura brasileira de enfermagem. Rev Latino-am Enfermagem; v. 13, n. 1, p.105-11, 2005.

CHIATTONE, H.B.C. Relato de experiência psicológica junto a crianças hospitalizadas. In: CAMON, V.A.A., editor. Psicologia hospitalar: a atuação do psicólogo no contexto hospitalar. São Paulo: Traço Ed.; 1984

COLLET, N.; OLIVEIRA, B.R.G. Enfermagem Pediátrica. Goiânia: AB, 2002.

COLLET, N.; ROCHA, S.M.N. Criança hospitalizada: mãe e enfermagem compartilhando o cuidado. Rev Latino-am Enfermagem. v. 12, n. 2, p. 191-7, 2004.

DAMAS, K.C.A.; MUNARI, D.B.; SIQUEIRA, K.M. Cuidando do cuidador: Reflexões sobre o aprendizado dessa habilidade. Revista Eletrônica de Enfermagem, v. 6, n. 2, p. 272-278, 2004. Disponível em:

http://www.fen.ufg.br/revista/revista6 2/pdf/R1 cuidad or.pdf. [acesso em 20 set. 2005].

ESPERIDIÃO, E.; MUNARI, D.B. Holismo só na Teoria: a trama de sentimentos do acadêmico de enfermagem sobre sua formação. Revista da Escola de Enfermagem da USP. v. 38, n. 3, p. 332-340, 2004.

LACAZ, C.P.C.; TYRRELL, M.A.R. A enfermagem e o cuidar de crianças com câncer - uma jornada pelo simbólico a partir da realidade vivenciada pelo universo familiar. Acta Paul Enf; v. 16, n. 6, p. 33-40, 2003.

LOBIONDO-WOOD, G.; HABER, J. Pesquisa em Enfermagem: Métodos, avaliação crítica e utilização. $4^{\mathrm{a}}$ ed. Rio de Janeiro: Guanabara-Koogan. 2001.

LONDON. Department of Healt and Social Security. Central Heat Services Council. The welfare of children in hospital: report of the committee. London: Her Majesty's Stationery Office; 1959.

MALDONADO, M.T.; CANELLA, P. Recursos de relacionamento para profissionais de saúde: a boa comunicação com clientes e seus familiares em consultórios, ambulatórios e hospitais. Rio de Janeiro: Reichmann \& Affonso Editores; 2003.

MINAYO, M.C. O desafio do conhecimento: pesquisa qualitativa em saúde. Rio de Janeiro: Hucitec/Abrasco, 1993.

MINAYO, M.C.; SANCHES, O. QuantitativoQualitativo: oposição ou complementaridade? Cad. Saúde Pública; v. 9, n. 3, p. 239-262, 1993.

MORIN, E. Os sete saberes necessários à educação do futuro. São Paulo (SP): Cortez; 2002.

MOTTA, M.G.C. O ser doente no tríplice mundo da criança, família e hospital: uma descrição fenomenológica das mudanças existenciais. 1998. 210p. Tese (Doutorado). Centro de Ciências da
Saúde, Universidade Federal de Santa Catarina. Florianópolis, SC:

MUNARI, D.B.; MERJANE, T.V.B.; CRUZ, R.M.M. A aplicação do modelo de educação de laboratório no processo de formação do enfermeiro. Rev Enfermagem UERJ, v. 13, n. 2, p. 263-269, 2005.

MUNARI, D.B.; RIBEIRO, V.; LOPES, M.M. Intervenção grupal com enfoque no cuidado emocional: relato de uma experiência. Rev Bras. Enfermagem, v. 55, n.4, p. 449-451, 2002.

MUNARI, D.B.; RODRIGUES, A.R.F. Enfermagem e Grupos. Goiânia: AB, 2003.

MUNIZ, J.R.; TAUNAY, M.S.D.'E. Grupos de Enfermagem no Hospital Geral. In: MELLO FILHO, J. Grupo e Corpo: Psicoterapia de grupo com pacientes somáticos. Porto Alegre: Artes Médicas Sul, 2000.

PAULI, M.C.; BOUSSO, R.S. Crenças que permeiam a humanização da assistência em unidade de terapia intensiva pediátrica. Rev Latino-am Enfermagem, v. 11, n. 3, p. 280-6, 2003.

RAMALHÃO, A.B.; DUPAS, G. Vivendo a ambivalência: o significado da visita para os pais de neonatos internados em unidade de tratamento intensivo. Acta Paul Enf., v. 16, n. 3, p. 41-50, 2003.

RIBEIRO, V.; MUNARI, D.B. Saúde mental em clientes cirúrgicos: o desenvolvimento de ações de enfermagem através do grupo de suport/apoio. Rev Bras. Enfermagem, v. 51, n.1, p. 147-164, 1998.

SANTEIRO, T.V.; SANTEIRO, F.R.M.; ANDRADE, I.R. Professor facilitador e inibidor da criatividade segundo universitários. Psicologia em Estudo, v. 9 , n. 1, p. 95-102, 2004.

SILVA, M.J.P. O amor é o caminho: maneiras de cuidar. São Paulo: Gente; 2000.

SUGANO, A.S.; SIGAUD, C.H.S.; REZENDE, M.A. A enfermeira e a equipe de enfermagem - Segundo mães acompanhantes. Rev Latino-am Enfermagem, v. 11, n. 5, p. 601-7, 2003.

VINOGRADOV, S.; YALOM, I. D. Manual de psicoterapia de grupo. Porto Alegre: Artes Médicas, 1992.

WERNET, M.; ÂNGELO, M. Mobilizando-se para a família: dando um novo sentido à família e ao cuidar. Rev Esc Enferm USP, v. 37, n. 1, p. 19-25, 2003.

Artigo original recebido em 19/03/2006 Aprovado para publicação em 30/04/2006: 